\title{
Vasomotor wave and blood pressure response to erect posture after operation for aortic coarctation
}

\author{
JENS SEHESTED, GEORG SCHULTZE` \\ From The University Clinic of Cardiovascular Surgery, Aarhus Kommunehospital, Aarhus, Denmark
}

SUMMARY Low frequency fluctuations (five to $10 / \mathrm{min}$ ) in blood pressure, that is vasomotor waves, were recorded in the erect position in 18 patients operated upon for an isolated aortic coarctation six to eight and a half years previously, and compared with vasomotor waves in six age matched normotensive controls with respect to frequency and amplitude.

The investigation was carried out by simultaneous intra-arterial blood pressure radiotelemetry recordings from the brachial and femoral arteries in all but four of the controls.

While the vasomotor wave frequency and blood pressure response to the erect posture was of the same order in the two groups, a highly significant difference was found with the amplitude of the vasomotor waves, being higher in the controls than in the patients.

Furthermore, the results seem to indicate a negative correlation between age at the time of surgical repair and vasomotor wave activity $(\mathrm{mmHg} / \mathrm{min})$.

It is suggested that the reduced vasomotor wave activity is brought about mainly by a disturbed input (from the baroreceptors) to the brainstem oscillator(s), caused by a combination of preoperative hypertension and prolonged exposure to high blood pressure.

With the introduction of intra-arterial blood pressure telemetry in $\operatorname{man}^{1}$ it has become possible to record blood pressure continuously in patients without their being disturbed by the measuring procedure. The purpose of the present investigation was to assess the vasomotor wave activity and blood pressure response to a sudden physiological change in the haemodynamics of postoperative patients with coarctation. This was done by telemetering the simultaneous intra-arterial pressures in the right brachial and femoral arteries in erect posture after a period of supine rest. Vasomotor wave activity was determined with respect to amplitude and frequency. Patients operated upon for an isolated aortic coarctation six to eight and a half years previously were compared with a group of normal age matched control subjects.

^Present address: Medizinische Klinik und Poliklinik, Klinikum Steglitz, Berlin, West Germany.

The study was supported by grants from The Danish Heart Association, Gross, , Abrahamson og Frue's mindelegat and Boeringer Ingelheim, Swedish division.

Accepted for publication 1 June 1982

\section{Subjects and methods}

Twenty-one patients who were hypertensive before operation but otherwise asymptomatic, now living a normal active life, were selected for the postoperative investigation. One turned out to have had an operation for an intracranial aneurysm one month earlier; in another a proper cannulation of the arteries could not be performed, and a third patient refused to participate. In the remaining 18 patients the investigation was carried out. Age at the time of study was $27 \cdot 8$ years $( \pm 9 \cdot 6 \mathrm{SD})$. None of the patients received any drugs during the study. All had normal values for standard blood tests including creatinine and urea, appeared normal at the physical examination, and had a normal postoperative chest $x$-ray. No smoking was allowed the last two hours before study. The blood pressure recordings were compared with those obtained under identical conditions from six normal healthy volunteers from the medical staff (age: 28.9 years $( \pm 7 \cdot 0 \mathrm{SD})$ ).

Since the first two normal subjects did not show any pressure gradients between the brachial and femoral arteries when in the upright posture, and in order to reduce the risk of injuries, only the brachial artery was 
cannulated in the last four control subjects.

Under local anaesthesia (4 to $6 \mathrm{ml}$ carbocain $0.5 \%$ ) a $120 \mathrm{~mm}$ long disposable polypropylene tiphole microcatheter (OD $1.2 \mathrm{~mm}$, ID $0.8 \mathrm{~mm}$, Vygon) supplied with an interior steel needle was inserted percutaneously into the artery. When the vessel had been entered the needle was withdrawn, and the catheter gently guided into the artery. The catheter was connected to the stop cock dome of a pressure transducer (P $37 \mathrm{~B}$, Statham) via a $1 \mathrm{~m}$ long disposable polyamide tube (OD $2.0 \mathrm{~mm}$, ID $1.0 \mathrm{~mm}$, Vygon). The right brachial artery was entered just above the antecubital fossa and the femoral artery was entered in the groin.

To prevent artefacts by movements, the catheters, connecting tubes, and transducers were anchored to the patient with sticking plaster. We made sure that the patient could move both extremities and body freely without kinking the catheter systems. To maintain the same distance between transducers and heart level, both during supine and upright position, the transducer holders were fixed side by side $2 \mathrm{~cm}$ above the level of the right atrium. Both transducer catheter systems were fitted with disposable equipment for continuous perfusion ( 2 to $4 \mathrm{ml}$ saline/hour), consisting of two reduction valves (Intraflo, Sorenson) and a pressure chamber which contained a disposable 0.31 plastic bottle of $0.88 \%$ saline, with 10000 IU heparin/ 1 added. The pressure chamber was designed as a modified and smaller version of the inflatable bags normally used for blood transfusions, and to keep the perfusate under a pressure of about $300 \mathrm{mmHg}$ for several hours. The telemetry transmitter and the perfusion system, altogether weighing about $1500 \mathrm{~g}$, were carried in a special belt (Fig. 1).

A major effort was made to minimise psychological influence. All steps in the study were carefully explained, and a good relation with the investigator was established in order to make the patients feel as relaxed as possible. After a couple of hours the patients became familiar with the equipment, and no one felt any restrictions because of it. Having understood that the purpose was to react as naturally as possible, the transducers were calibrated against a column of mercury, and the patient put to bed for 20 minutes immediately afterwards followed by a 10 minute period standing beside the bed. We checked that the shift in posture was carried out identically by each patient. The investigation was done between 6 and $7 \mathrm{pm}$ in all patients after a light standard hospital meal at about 5 pm.

During the study the blood pressure curves were followed on an oscilloscope to ensure that no artefacts such as kinking, damping, catheter whips, or electrical noise were interfering. At the end of the investigation the transducers were calibrated again to check that no

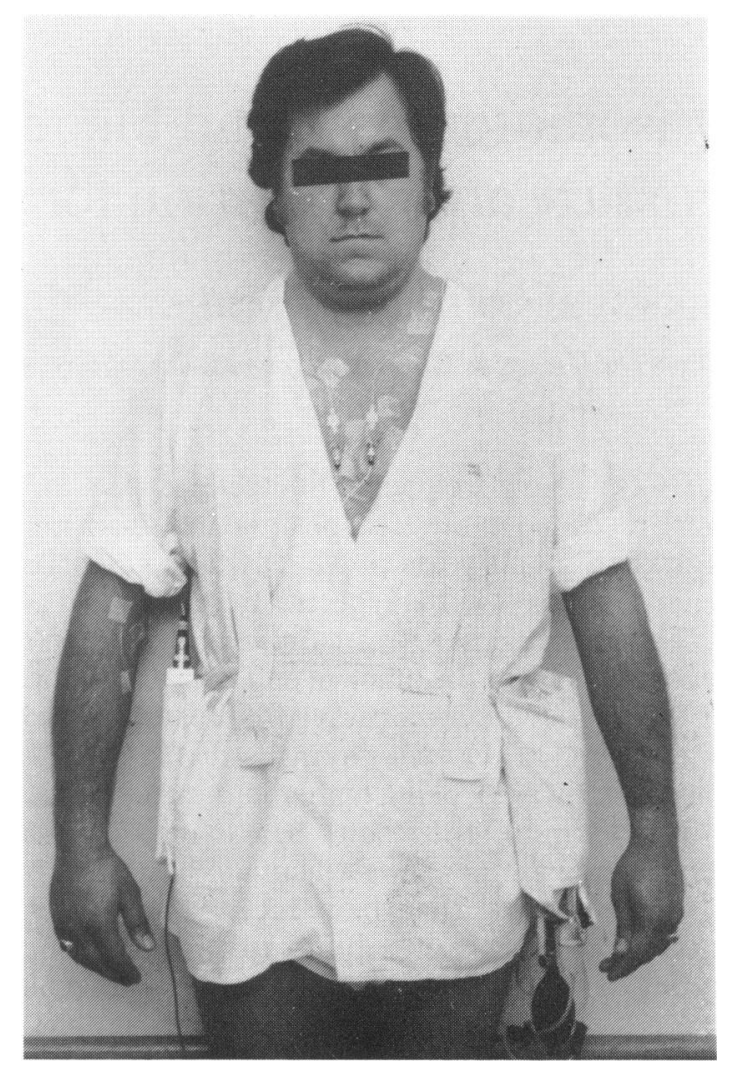

Fig. 1 The telemetry system consisting of a radio transmitter (to the patient's right) and a perfusion device (to the left in the belt). The two transducers are fixed to the chest of the patient.

drifting had occurred. The removal of the catheters caused trouble in only one patient, who developed a haematoma on the upper arm; recovery, however, was uneventful.

The data on patients and volunteers are given in the Table. Except for case 2 where the cuff method was applied for measuring the blood pressure, all preoperative pressures listed are intra-arterial, obtained under local anaesthesia during supine rest. Case 3 had Turner's syndrome.

The radiotelemetry transmitter (Danica) had two analogue inputs for the pressure transducers. The blood pressure waves were transmitted via a multiplex FM modulating system of a crystal controlled frequency at $164.650 \mathrm{MHz}$. The transmitter was powered by a $\mathrm{Ni} / \mathrm{Cd}$ rechargeable battery permitting continuous operation for at least eight hours. The two blood pressure outputs from the receiver (Danica) were simultaneously fed into a multichannel instrumentation tape recorder (Hewlett-Packard HP 3964A) for later analysis as well as into an oscilloscope allowing immediate inspection and checking of both blood 
Table Individual data on patients and control subjects

\begin{tabular}{|c|c|c|c|c|c|c|c|c|c|c|}
\hline \multirow[t]{2}{*}{$\begin{array}{l}\text { Case No. } \\
\text { and sex }\end{array}$} & \multirow[t]{2}{*}{$\begin{array}{l}\text { Age (y) at operation/ } \\
\text { Age (y) at study }\end{array}$} & \multirow[t]{2}{*}{$\begin{array}{l}\text { Type of repair } \\
(+/- \text { graft })\end{array}$} & \multicolumn{6}{|c|}{$\begin{array}{l}\text { Right brachial artery blood pressures and systolic } \\
\text { pressure gradients }(>5) \text { in } \mathrm{mmHg}\end{array}$} & \multirow[t]{2}{*}{$\begin{array}{l}\text { Vasomotor } \\
\text { waves/min }\end{array}$} & \multirow[t]{2}{*}{$\begin{array}{l}\text { Vasomotor activity } \\
\text { ( } \mathrm{mmHg} / \mathrm{min})\end{array}$} \\
\hline & & & $\begin{array}{l}\text { Before op } \\
\text { Rest }\end{array}$ & eration & $\begin{array}{l}\text { After oper } \\
\text { Rest }\end{array}$ & ation & Standing & & & \\
\hline $\begin{array}{l}1 \mathrm{~F} \\
2 \mathrm{M} \\
3 \mathrm{~F} \\
4 \mathrm{~F} \\
5 \mathrm{M} \\
6 \mathrm{M} \\
7 \mathrm{M} \\
8 \mathrm{M} \\
9 \mathrm{M} \\
10 \mathrm{M} \\
11 \mathrm{M} \\
12 \mathrm{~F} \\
13 \mathrm{M} \\
14 \mathrm{M} \\
15 \mathrm{~F} \\
16 \mathrm{M} \\
17 \mathrm{~F} \\
18 \mathrm{~F}\end{array}$ & $\begin{array}{l}10 \cdot 0 / 17 \cdot 7 \\
10 \cdot 6 / 17 \cdot 3 \\
11 \cdot 2 / 18 \cdot 9 \\
12 \cdot 3 / 20 \cdot 1 \\
12 \cdot 8 / 18 \cdot 7 \\
14 \cdot 2 / 21 \cdot 7 \\
14 \cdot 3 / 21 \cdot 9 \\
15 \cdot 9 / 22 \cdot 5 \\
17 \cdot 9 / 24 \cdot 8 \\
18 \cdot 9 / 27 \cdot 4 \\
19 \cdot 7 / 26 \cdot 1 \\
20 \cdot 5 / 26 \cdot 6 \\
20 \cdot 8 / 27 \cdot 4 \\
22 \cdot 5 / 29 \cdot 8 \\
32 \cdot 6 / 39 \cdot 2 \\
34 \cdot 1 / 42 \cdot 4 \\
37 \cdot 0 / 44 \cdot 1 \\
39 \cdot 5 / 48 \cdot 0\end{array}$ & $\begin{array}{l}- \\
- \\
+ \\
- \\
- \\
- \\
- \\
- \\
+ \\
+ \\
- \\
- \\
+ \\
- \\
- \\
- \\
+ \\
+\end{array}$ & $\begin{array}{l}128 / 85 \\
150 / 90 \\
155 / 95 \\
138 / 88 \\
165 / 90 \\
130 / 67 \\
176 / 88 \\
178 / 107 \\
210 / 91 \\
184 / 94 \\
175 / 100 \\
180 / 90 \\
187 / 95 \\
183 / 105 \\
145 / 85 \\
156 / 75 \\
210 / 90 \\
120 / 73\end{array}$ & $\begin{array}{l}17 \\
45 \\
65 \\
66 \\
40 \\
22 \\
86 \\
63 \\
77 \\
54 \\
90 \\
70 \\
67 \\
57 \\
15 \\
39 \\
90 \\
28\end{array}$ & $\begin{array}{l}113 / 62 \\
168 / 68 \\
133 / 66 \\
117 / 69 \\
120 / 70 \\
104 / 60 \\
150 / 71 \\
112 / 60 \\
130 / 66 \\
158 / 80 \\
132 / 70 \\
111 / 52 \\
161 / 82 \\
119 / 61 \\
110 / 61 \\
105 / 50 \\
117 / 59 \\
137 / 67\end{array}$ & $\begin{array}{l}6 \\
- \\
- \\
- \\
20 \\
21 \\
\frac{38}{10} \\
6 \\
- \\
- \\
-\end{array}$ & $\begin{array}{l}125 / 75 \\
173 / 82 \\
143 / 74 \\
136 / 88 \\
132 / 86 \\
106 / 70 \\
144 / 82 \\
128 / 73 \\
162 / 90 \\
176 / 107 \\
138 / 80 \\
119 / 67 \\
180 / 102 \\
128 / 76 \\
156 / 98 \\
122 / 66 \\
146 / 77 \\
154 / 83\end{array}$ & $\begin{array}{l}\overline{29} \\
9 \cdot 5 \\
- \\
- \\
\overline{14} \\
19 \\
7 \cdot 5 \\
14 \\
- \\
- \\
- \\
- \\
- \\
-\end{array}$ & $\begin{array}{l}8 \\
7 \cdot 3 \\
7 \cdot 3 \\
8 \cdot 3 \\
6 \cdot 3 \\
7 \cdot 3 \\
7 \cdot 7 \\
6 \cdot 7 \\
7 \cdot 3 \\
5 \\
6 \\
7 \cdot 3 \\
8 \cdot 3 \\
5 \cdot 7 \\
8 \cdot 3 \\
6 \cdot 3 \\
8 \cdot 7 \\
7 \cdot 7\end{array}$ & $\begin{array}{r}49.38 \\
97 \cdot 77 \\
66.99 \\
82 \cdot 30 \\
50 \cdot 04 \\
101 \cdot 39 \\
58 \cdot 67 \\
44.44 \\
63 \cdot 37 \\
104.93 \\
77 \cdot 03 \\
63.37 \\
41 \cdot 15 \\
33.59 \\
43.21 \\
43.34 \\
43.33 \\
43.81\end{array}$ \\
\hline $\begin{array}{l}\text { Mean } \\
\pm S D\end{array}$ & $\begin{array}{r}27.8 \\
9.6\end{array}$ & & $165 / 89$ & & $\begin{array}{l}128 / 65 \\
20 \cdot 0 / 8 \cdot 2\end{array}$ & & $\begin{array}{l}143 / 82 \\
20 \cdot 8 / 11 \cdot 6\end{array}$ & & $\begin{array}{l}7 \cdot 19 \\
1.0\end{array}$ & $\begin{array}{l}61 \cdot 56 \\
22 \cdot 50\end{array}$ \\
\hline $\begin{array}{l}\text { Controls } \\
1 M \\
2 M \\
3 F \\
4 M \\
5 M \\
6 M\end{array}$ & $\begin{array}{l}24.6 \\
25.0 \\
25.6 \\
27.0 \\
28.3 \\
42.9\end{array}$ & & & & $\begin{array}{r}133 / 80 \\
110 / 75 \\
134 / 73 \\
120 / 75 \\
102 / 55 \\
95 / 53\end{array}$ & & $\begin{array}{l}132 / 88 \\
119 / 87 \\
144 / 83 \\
112 / 75 \\
145 / 82 \\
118 / 72\end{array}$ & & $\begin{array}{l}9.7 \\
6.7 \\
5.7 \\
6.7 \\
7 \cdot 3 \\
9.7\end{array}$ & $\begin{array}{r}106 \cdot 33 \\
51 \cdot 00 \\
86 \cdot 74 \\
83 \cdot 33 \\
109 \cdot 14 \\
119 \cdot 34\end{array}$ \\
\hline $\begin{array}{l}\text { Mean } \\
\pm S D\end{array}$ & $\begin{array}{r}28 \cdot 9 \\
7 \cdot 0\end{array}$ & & & & $\begin{array}{l}116 / 69 \\
16 \cdot 1 / 11 \cdot 5\end{array}$ & & $\begin{array}{l}128 / 81 \\
14 \cdot 1 / 6 \cdot 4\end{array}$ & & $\begin{array}{l}7.63 \\
1.7\end{array}$ & $\begin{array}{l}92.65 \\
24.6\end{array}$ \\
\hline Difference & NS & & & & NS & & NS & & NS & $p<0.008$ \\
\hline
\end{tabular}

pressure curves. In persons having only the brachial artery cannulated a single channel transmitter was used (Hellige).

The two catheters, connecting tubes, transducers including the perfusion device, and the telemetry system were tested together, before and after the investigation for static and dynamic properties. No differences between the two chains of measuring were found. The static response, tested against a mercury column in steps of $50 \mathrm{mmHg}$, was better than $\pm 1 \%$ over the range 0 to $300 \mathrm{mmHg}$. The dynamic response was determined by the step response method as well as by the use of a sine wave generator, a power amplifier, and an electrodynamic pressure converter based on a coil and membrane system. The sine wave pressure amplitude in the test chamber was controlled by a Millar micro tip catheter pressure transducer (model PC 350) with a natural frequency above $20 \mathrm{kHz}$.

The telemetry system had a natural frequency of 22 $\mathrm{Hz}$ and a damping coefficient of 0.36 (minimum values).

Informed consent was obtained from all persons involved.

\section{ANALYSIS}

The tapes were replayed at the recording speed, and the blood pressure curves were plotted using an analogue/digital converter (Hewlett-Packard HP 47310A), a minicomputer (Hewlett-Packard 9825), and a plotter (Hewlett-Packard HP 7225A). The digitising frequency was $25 \mathrm{~Hz}$ per channel, and values of systolic and diastolic pressures were stored in the computer. By plotting the enveloping curves together and with separate colours, simultaneous variations in the systolic and diastolic pressures as well as the pressure gradients between the brachial and femoral arteries could easily be shown. In the case of cannulation of the brachial artery alone, the blood pressure curve was recorded by a chart recorder (paper speed $0.5 \mathrm{~mm} / \mathrm{s}$ ).

As a control measure, a number of sequences, each lasting several minutes, was recorded both by the computer plotter and chart recorder. By comparison, no differences were found either between the appearance of a pressure curve or the indication of systolic and diastolic pressure levels.

Listed blood pressure values (Table) represent the 
mean during a three minute period after a 15 minute rest supine and after at least one minute of standing erect.

The amplitudes of the vasomotor waves ( 5 to $10 / \mathrm{min}$ ) during standing were calculated manually by measuring the vertical distance in $\mathrm{mmHg}$ from the summit to the following nadir on the enveloping systolic pressure

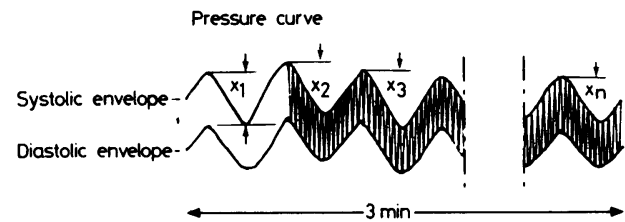

Fig. 2 Calculation of vasomotor wave activity: $\left(x_{1}+x_{2}+x_{3}+\ldots x_{n}\right) / 3=m m H g / m i n$. curve from the brachial artery. A summit was defined as a peak to which the pressure increased, and from which the pressure decreased. The opposite criteria defined a nadir. A stepwise increase or decrease in pressure is represented by only the highest and lowest values. After standing for one minute (allowing blood pressure level to stabilise) all the peaks and corresponding nadirs were measured during a three minute period. The results are given as vasomotor wave activity in $\mathrm{mmHg} / \mathrm{min}$, representing the mean value of the added vasomotor wave amplitudes during one minute (Fig. 2).

\section{STATISTICS}

The Mann-Whitney-Wilcoxon rank sum test was applied when groups were compared. Regression analyses were performed by the SPSS program. Level of significance was set at $\mathbf{p}<0.05$.

(a)

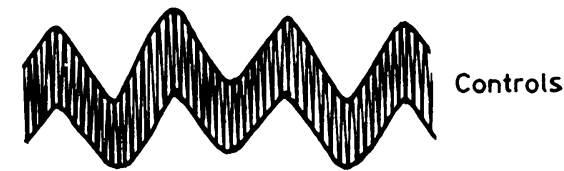

Pressure curves (A Brach)

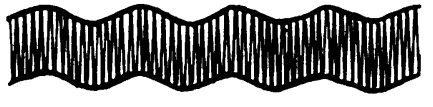

Patients

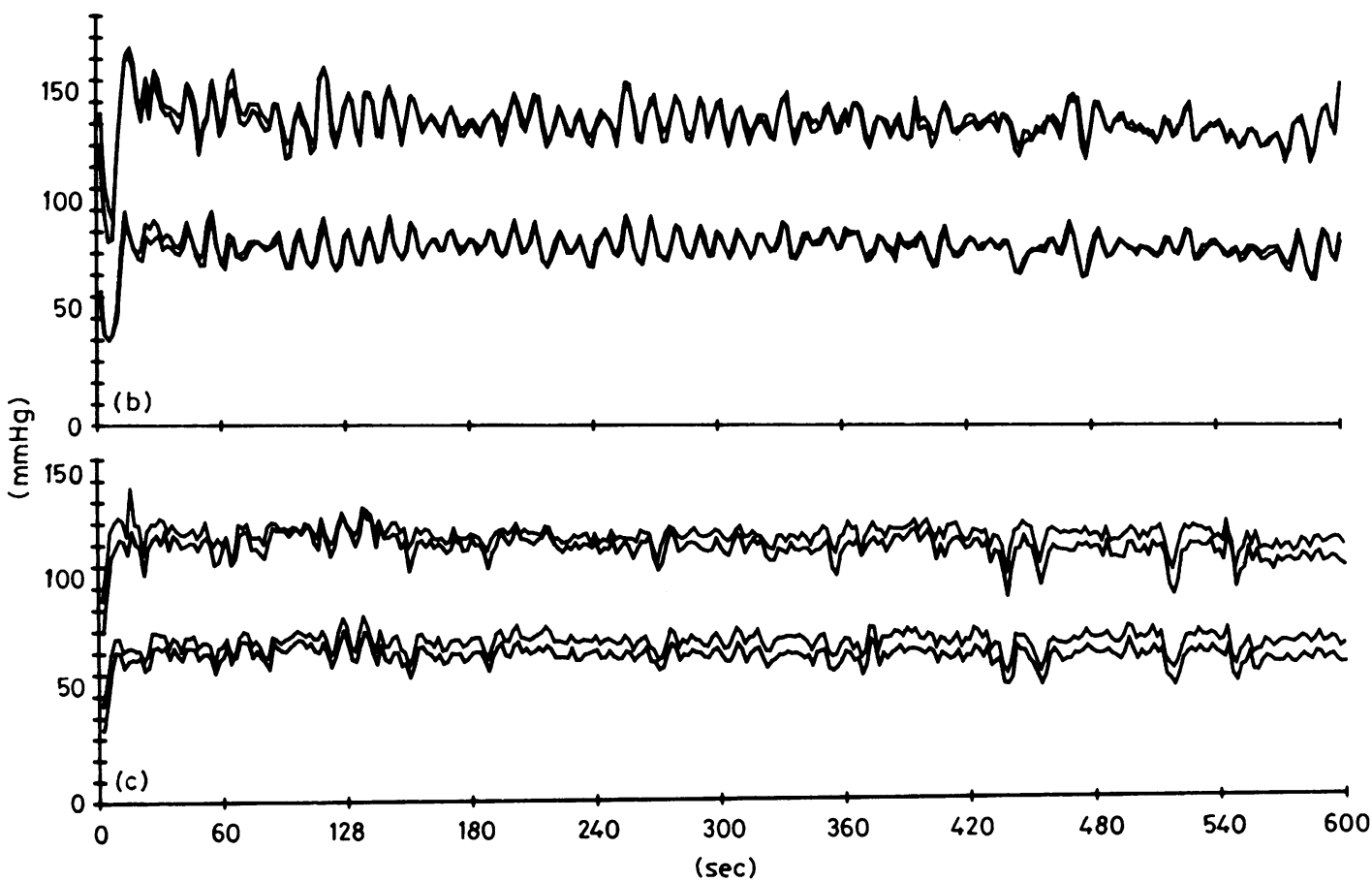

Fig. 3 (a) The difference between control subjects and patients shown schematically. (b) Original enveloping systolic and diastolic pressure curves during standing from a control subject (case 3). (c) A patient (case 1). The latter shows a modest gradient between the brachial and femoral arteries which is not seen in the control. In both cases the pressure drop, after change in position from supine to upright standing, is seen at the beginning of curves. 


\section{Results}

While the enveloping curves were smooth during supine rest in both the patients and the controls, and only differed with regard to the level of pressure and degree of pressure gradients, considerable differences were found during standing (Fig. 3). Even by visual inspection a much greater activity of the vasomotor waves could be seen in the normal control subjects when compared with the patients. This was confirmed by the measurements which showed a mean value of $92.65 \pm 24.6 \mathrm{SD} \mathrm{mmHg} / \mathrm{min}$ in the normal subjects, and $61.6 \pm 22.5 \mathrm{SD} \mathrm{mmHg} / \mathrm{min}$ in the patients $(p<0.008)$. It was further found that this difference resulted from a larger amplitude of the vasomotor waves in the normal control subjects than in the patients as the number of waves per minute was of the same order in the two groups: $7.63 \pm 1.7 \mathrm{SD}$ in the controls, and 7.19 $\pm 1.0 \mathrm{SD}$ in the patients (Table).

A significantly lower activity of $59.5 \pm 19.7 \mathrm{SD}$ $\mathrm{mmHg} / \mathrm{min}(\mathrm{p}<0.007)$ was also found in the 12 patients who obtained a normal upright postoperative systolic pressure of lower than $150 \mathrm{mmHg}$ when compared with the control subjects. The two groups did not differ with respect to age, systolic blood pressure, or number of waves per minute: $25 \cdot 9 \pm 8 \cdot 7$ SD years for patients, and $28.9 \pm 7$ SD years for control subjects, $131 \pm 11 \cdot 7 \mathrm{SD}$ vs $128 \pm 14 \cdot 1 \mathrm{SD} \mathrm{mmHg}$, and $7 \cdot 13 \pm 0 \cdot 9 \mathrm{SD}$ vs $7 \cdot 63 \pm 1 \cdot 7 \mathrm{SD}$ waves/min. No correlation was found between vasomotor wave activity and systolic pressure in the brachial artery of the patients. A negative correlation, however, was found between age at the time of operation and vasomotor wave activity $(\mathrm{p}<0.02$, Fig. 4). The correlation coefficient was -0.49 . The vasomotor wave activity of the femoral enveloping systolic pressure curve always closely

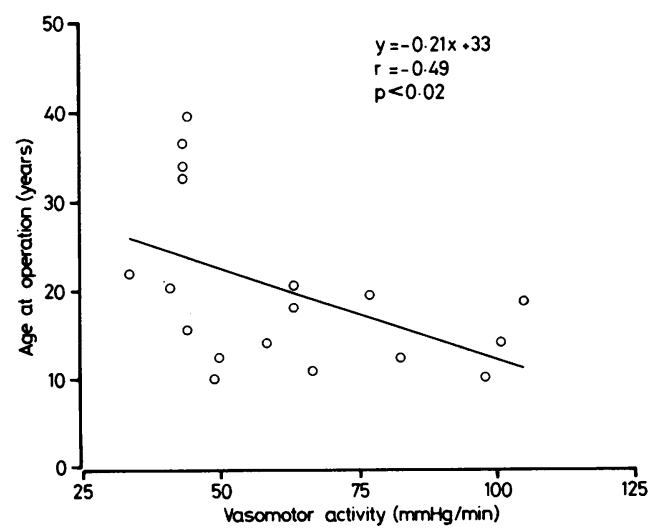

Fig. 4 The correlation between age of the patients at the time of operation and the vasomotor wave activities. resembled that of the brachial curve even in the presence of a systolic pressure gradient; the course of the vasomotor waves did not look like a damped wave phenomenon.

No significant differences between the normal controls and the patients were found with regard to systolic pressure $(128 \pm 14 \cdot 1 \mathrm{SD} \mathrm{mmHg}$ in the control subjects, and $143 \pm 20.8 \mathrm{SD} \mathrm{mmHg}$ in the patients). During supine rest four patients had a systolic pressure gradient across the resected area of the aorta exceeding $10 \mathrm{mmHg}$ (range 20 to $38 \mathrm{mmHg}$ ). During standing these four patients had a slight decrease in the gradient (range 14 to $29 \mathrm{mmHg}$ ).

During the 10 minute period of standing a modest decrease in pressure was seen in all (ranges in patients were: 0 to $13 \mathrm{mmHg}$ systolic and 0 to $10 \mathrm{mmHg}$ diastolic, and in the controls: 0 to $8 \mathrm{mmHg}$ systolic and 0 to $3 \mathrm{mmHg}$ diastolic). In all persons studied the change from supine to upright position caused a transitory drop in pressure. In 11 of the 18 patients this was accompanied by a systolic pressure gradient exceeding $10 \mathrm{mmHg}$ (range: 12 to $42 \mathrm{mmHg}$ ).

Finally, the change in posture caused an increase in mean arterial pressure in all except one of the normal subjects, who showed a drop of $2.7 \mathrm{mmHg}$. The mean increase was of the same order: $12.7 \mathrm{mmHg}$ in the controls (range: -2.7 to $32.3 \mathrm{mmHg}$ ) and $16.2 \mathrm{mmHg}$ in the patients (range: 5.3 to $40 \mathrm{mmHg}$ ).

Mean heart rates, used to detect gross variations in autonomic tone, were identical: 71.3 vs 70.8 at rest and 91.9 vs $91.7 / \mathrm{min}$ during standing, patients and controls, respectively.

\section{Discussion}

It seems that asymptomatic patients operated on for an isolated aortic coarctation show a normal pressure response to standing, from 5.9 to 8.5 years after operation. The study further shows that systolic hypertension, that is greater than $150 \mathrm{mmHg}$, may occur during standing without a systolic pressure gradient between the brachial and femoral arteries exceeding 10 $\mathrm{mmHg}$, normally considered as evidence of a re- or rest stenosis. ${ }^{2-4}$ This corresponds with the lack of correlation between the size of the anastomosis and blood pressure readings during exercise, ${ }^{5}$ indicating that factors other than a re- or rest stenosis might be responsible for a high postoperative blood pressure.

This study appears to be the first on vasomotor wave activity and blood pressure response to change in posture from lying to standing in postoperative patients with coarctation. Comparisons with other investigations into hypertension unconnected with coarctation are difficult since we studied upright standing in contrast to various tilt tests. ${ }^{67}$ In other studies again the cuff method has been used for measuring 
blood pressure during standing. ${ }^{89}$ None of our patients, however, showed hypotension on standing indicative of severe vascular disease, ${ }^{6}$ and we found no differences in diastolic pressures as described in borderline hypertension ${ }^{9}$ between normal subjects and patients.

The continuous recording of intra-arterial pressures during standing, however, showed a highly significant difference of $p<0.008$ in vasomotor wave activity between patients and control subjects. This difference was the result of a larger amplitude in the normal subjects than in the patients, the number of waves being the same in both groups $(\mathrm{p}>0.8)$.

The lack of correlation between vasomotor wave activity and systolic blood pressure of the patients and the reduced activity when compared with the control series of comparable age and blood pressure seems to indicate that the altered vasomotor wave activity is caused mainly by the preoperative condition dominated by hypertension. This is further supported by the reduced activity even in patients with a normotensive response to standing after operation.

The origin of the vasomotor waves is complex and not completely understood. Though often called "respiratory waves" it is well documented, however, that they are the peripheral cardiovascular response to a rhythmic central activity and not caused merely by intrathoracic pressure variations during ventilation having a frequency of both lower than (as in this study), equal to, or even higher than that of respiration. ${ }^{10}$

The respiratory rhythmicity is coupled with a sympathetic vagal oscillation based on and modified by afferents from mainly pulmonary stretch receptors, chemoreceptors, and baroreceptors. "1 Furthermore, the effectiveness of both chemo- and baroreceptor reflexes is influenced by the central respiratory rhythm, even in the absence of lung movements. ${ }^{12}$

The diminished amplitude but normal frequency of the vasomotor waves in our patients when compared with the controls might then be caused by alterations in the afferents, including receptors, and/or the central oscillatory mechanism(s) and/or the efferents, including effector organs. Few of these factors have been investigated in aortic coarctation: it has been shown that the resistance to flow is greater in the upper extremities than in the lower ones even years after operation, 1314 indicating structural changes in the resistance vessels (effector organs) of the upper limbs. The reduced or "flattened" vasomotor waves in our patients, however, were present in both the upper extremity (brachial artery) and the lower extremity (femoral artery), thus posing the importance of the resistance vessels in this context. The baroreceptor sensitivity in postoperative patients was found to be "somewhat decreased" when compared with the control subjects, ${ }^{15}$ but the results are difficult to interpret since angiotension, with a known chronotropic effect, was used. On the other hand, pharmacodynamic and morphometric studies of the aorta in patients with coarctation have given results compatible with a more rigid and thus less distensible precoarctational aorta in comparison with the aorta distal to the coarctation and with the aortas of control subjects. The nature of these vascular changes is of a kind (significantly more collagen in the precoarctational aorta) that could imply a more permanent disturbance in the baroreceptor function. ${ }^{16}$

It is an open question how these findings correlate with the diminished vasomotor wave activity found in our patients. Since both a high preoperative age and high blood pressure seem to reduce vasomotor wave oscillations, however, and at the same time these two factors influence reactivity of the precoarctational aorta, ${ }^{16}$ it is tempting to attribute the altered vasomotor wave pattern to disturbances in the behaviour of the afferent baroreceptors. It has thus been shown that not only high blood pressure ${ }^{17} 18$ but also increasing age ${ }^{18}$ reduce baroreceptor sensitivity (measured by the response to intravenous injection of phenylephrine) and further that these two variables probably act independently.

Although the small number of controls in our study does not warrant statistical analysis and the correlation in patients between age and vasomotor wave activity, while statistically significant, is weak, the existence, however, of an age dependant reduction in the activity in all subjects cannot be completely denied. At present no information is available from other larger series.

With all the unsettled questions in mind, it might be concluded that the analysis of vasomotor waves, provoked by standing, could be an important indication of vascular and/or baroreceptor disorder in aortic coarctation, and perhaps in other hypertensive states as well.

We are indebted to software engineer Jan Schoubo Petersen, Institute of Datalogy, Aarhus University and electronic engineer Jørgen Gormsen, Jydsk Teknologisk Institut, Aarhus, for skilful technical assistance.

\section{References}

1 Bachmann $\mathrm{K}$, Thebis J. Die drahtlose Ubertragung kontinuierlicher direkter Blutdruckmessungen. Zeitschrift fur Kreislaufforschung 1967; 56: 188-91.

2 Maron BJ, Humphries JO, Rowe RD, Mellits ED. Prognosis of surgically corrected coarctation of the aorta. Circulation 1973; 47: 119-26.

3 Nanton MA, Olley PM. Residual hypertension after coarctectomy in children. Am $\mathcal{F}$ Cardiol 1976; 37: 769-72. 
4 Hubbell MM Jr, O’Brien RG, Krovetz LJ, Mauck HP, Tompkins DG. Status of patients 5 or more years after correction of coarctation of the aorta over age one year. Circulation 1979; 60: 74-80.

5 Hanson E, Eriksson BO, Sörensen SE. Intra-arterial blood pressures at rest and during exercise after surgery for coarctation of the aorta. Eur $\mathcal{F}$ Cardiol 1980; 11: 24557.

6 Frolich ED, Tarazi RC, Ulrych M, Dunstan HP, Page IH. Tilt test for investigating a neural component in hypertension. Circulation 1967; 36: 387-93.

7 Sannerstedt R, Julius S, Conway J. Hemodynamic responses to tilt and beta-adrenergic blockade in young patients with borderline hypertension. Circulation 1970; 42: 1057-64.

8 Abelmann WH, Fareeduddin K. Increased tolerance of orthostatic stress in patients with heart disease. Am $\mathcal{J}$ Cardiol 1969; 23: 354-63.

9 Hull DH, Wolthuis RA, Cortese T, Longo MR Jr, Triebwasser JH. Borderline hypertension versus normotension: differential response to orthostatic stress. Am Heart f 1977; 94: 414-20.

10 Koepchen HP. Die Blutdruckrhytmik. Darmstadt: Dietrich Steinkopff Verlag, 1962: 100-1.

11 Koepchen HP. The respiratory-cardiovascular brainstem oscillator in context of afferent and central excitatory and inhibitory systems. In: Koepchen HP, Hilton SM, Trzebski A, eds. Central interaction between respiratory and cardiovascular control systems. Berlin, Heidelberg, New York: Springer-Verlag, 1980: 197-203.

12 McCloskey DI. Respiratory modulation of vagal and sympathetic reflex effects of chemoreceptor and baro- receptor origin. In: Koepchen HP, Hilton SM, Trzebski $\mathrm{A}$, eds. Central interaction between respiratory and cardiovascular control systems. Berlin, Heidelberg, New York: Springer-Verlag, 1980: 188-94.

13 Šamánek M, Goetzová J, Fišerová J, Škovránek J. Differences in muscle blood flow in upper and lower extremities of patients after correction of coarctation of the aorta. Circulation 1976; 54: 377-81.

14 Sivertsson R, Hansson E, Eriksson B. Hemodynamic signs indicating structural vascular changes of hypertensive type after surgery for aortic coarctation. Acta Med Scand 1978; 625, suppl: 116-21.

15 Hanson E. Coarctation of the aorta. A long-term followup study after surgery. Scand $\mathcal{F}$ Thorac Cardiovasc Surg $1980 ; 24$, suppl: $1-31$.

16 Sehested J, Baandrup U, Mikkelsen E. Different reactivity and structure of pre- and poststenotic aorta in human coarctation. Implications for baroreceptor function. Circulation 1982; 65: 1060-5.

17 Bristow JD, Honour AJ, Pickering GW, Sleight P, Smyth HS. Diminished baroreflex sensitivity in high blood pressure. Circulation 1969; 39: 48-54.

18 Gribbin B, Pickering TG, Sleight P, Peto R. Effect of age and high blood pressure on baroreflex sensitivity in man. Circ Res 1971; 29: 424-31.

Requests for reprints to Dr Jens Sehested, Department of Clinical Physiology, Aalborg Sygehus Syd, 9000 Aalborg, Denmark. 